\title{
Has the time come to evaluate studies results before their adoption as standards of care in the neonatal units?
}

Volume 2 Issue 2 - 2015

Guillermo Godoy

Department of Pediatrics and Obstetrics, University of Alabama, USA

\section{Editorial}

The need and pressure to publish research in the peer review medical literature has created a immense amount of results that, in some instances, have not been validated by follow up studies. ${ }^{1,2}$ Usually, the preliminary data of new discoveries in neonatal care, that promised great improvements in the survival and/or decrease morbidities and better quality of life, are done with great intentions and expectations and many times encompass the passion and lifelong commitment of the investigator to prove his/her theory. ${ }^{2,3}$ Follow up studies to confirm the results of these preliminary findings often fail to show the claim or show serious side effects and complications. ${ }^{3-7}$

The problem is that the medical community, when these positive results are published, tends to accept them as the new standard of care. These new advances are incorporated in hospitals and unit protocols and are offered to sick newborns without the benefit of statistically valid methods and medical due diligence. ${ }^{7}$ Reports that have not been done with appropriate prospective randomization, blind allocation and stratification of selected target population, and with an adequate power and Beta error scrutiny, should be interpreted with caution. ${ }^{8}$ All of these claims should be done ethically, and contain medical and statistic methods that study the possible complications and side effects of such procedures, before adopted as "golden standards".

A recent example is the use of iNO in premature infants. ${ }^{9}$ The preliminary results published by Dr. R. Ballard found in her population that iNO improved pulmonary outcomes. After that report, several studies (meta analysis) failed to confirm Dr. Ballard findings. ${ }^{10,11}$ Even further, a recent propensity score modeling study by the National Institute of Health (NIH), in their generic database (GDB) that included data from 4979 of infants $>22$ and $<29$ weeks gestation, found that the exposure to iNO in this population was associated with more severe outcomes. ${ }^{11}$ I suggest to proceed with caution before the neonatal care community adopts these new findings as facts. We should read these reports for what they are, preliminary data that should be verified by follow up studies that are conducted in an ethical, medically sound and statistically well- designed manner. ${ }^{7}$

Many manuscripts end their conclusions with the reminder that their findings are limited to a small number or particular population and the need for further multicenter trials, to prove or disprove them. We should develop a group of investigators around the globe that take that challenge and in a systematic, well thought multi-center, prospective, randomized, blind method and study these preliminary results. The challenge is deep and extensive, but a well-organized and committed group could answer these important questions.
Correspondence: Guillermo Godoy, Department of Pediatrics and Obstetrics, University of Alabama, CCHS, DCH Health System, I 364 Downing Ridge, Tuscaloosa, AL. 35406, USA, Tel (205) 752-9739, Fax 205) 345-527. Email guillermo46I@comcast.net

Received: February 05, 2015 | Published: March 27, 2015

\section{Acknowledgments}

None.

\section{Conflicts of interest}

Author declares there are no conflicts of interest.

\section{Funding}

None.

\section{References}

1. Schachman KH. From "Publish or Perish" to "Patent and Prosper". The Journal of Biological Chemistry. 2006;281(11):6889-6903.

2. Botch TM. Infant Feeding-Weaning. In: Keating JM (Ed.), Cyclopaedia of the Diseases of Children, Medical and Surgical. Vol 1, JB Lippincott, Philadelphia, USA. 1980. p. 270-329.

3. Crosse VM, Hickmans EM, Howarth BE, et al. The value of human milk compared with other feeds for premature infants. Arch Dis Child. 1954;29(145):178-195.

4. Terry TL. Retrolental Fibroplasia in the Premature Infant: V. Further Studies on Fibroplastic Overgrowth of the Persistent Tunica Vasculosa Lentis. Trans Am Ophthalmol Soc. 1944;42:383-396.

5. Reece AB. An epitaph for retrolental fibroplasia. Am J Ophthalmol. 1955;40(2):267-269.

6. Silverman WA. Medical inflation. Perspect Biol Med. 1980;23(4):617-637.

7. Magnus D, Wilfond BS. Research on Medical Practices and the ethics of disclosure. Pediatrics. 2015;135(2):208-210.

8. Strasak AM, Zaman Q, Pfeiffer KP, et al. Statistical errors in medical research - a review of common pitfalls. Swiss Med Wkly. $2007 ; 137(3-4): 44-49$. 
9. Ballard RA, Troug WE, Cnaan A, et al. Inhaled nitric oxide in preterm infants undergoing mechanical ventilation. $N$ Engl J Med. 2006;355(4):343-353.

10. Barrington KJ, Finner N. Inhaled nitric oxide for respiratory failure in preterm infants. Cochrane Database Syst Rev. 2010;(12):CD000509.
11. Donohue PK, Gilmore MM, Cristofalo E, et al. Inhale nitric oxide in premature infants: a systematic review. Pediatrics. 2011; 127(2):e414e422. 